This paper is published in the open archive of Mid Sweden University

DIVA http://miun.diva-portal.org

with permission of the publisher

Citation for the peer-reviewed published paper:

Klinga N, Höglund H, Sandberg C. Paper properties of TMP and CTMP

handsheets from spruce, as affected by the solids content from pressing. ;

Nordic Pulp \& Paper Research Journal. 2007;22(4):475-480.

URL to article at publishers site:

http://dx.doi.org/10.3183/NPPRJ-2007-22-04-p475-480 


\title{
Paper properties of TMP and CTMP handsheets from spruce, as affected by the solids content from pressing
}

\author{
Niklas Klinga and Hans Höglund, Mid Sweden University, Sundsvall, Christer Sandberg, Holmen Paper Development Centre, Norrköping, Sweden
}

KEYWORDS: Laboratory sheet, TMP, CTMP, Dryness, Solids content, Mechanical properties, Pressing, Drying

SUMMARY: This paper discusses how the properties of dry handsheets from two different mechanical pulps and one chemithermomechanical pulp and their respective long fibre fractions depend on the level of dryness to which the sheets are pressed at high temperature. Sheets were pressed and dried to different dryness levels at $400 \mathrm{kPa}$ and $93^{\circ} \mathrm{C}$ in a modified Rapid Köthen dryer. Prior to testing of the physical properties, the sheets were dried without pressure at room temperature to full dryness and kept in a conditioning room. This was performed with the aim of evaluating the consolidation and development of final strength properties with respect to dryness after a press section in a paper machine.

The most interesting finding from these trials was that the increase in density and strength were far from linear with increased press dryness, especially for the long fibre fractions when looking at the Z-strength development. There was a distinct inflection of the curve when the sheets reached a press dryness level of some $50 \%$. The most important dryness interval for internal strength development was found between 50 and $80 \%$.

The fact that most paper and board machines press the sheet to only some $50 \%$ dryness, before feeding it into the drying section, implies that much of the inherent strength potential of mechanical pulps may be unexploited. Further research on pressing to higher dryness levels will in the future be continued at FSCN at Mid Sweden University.

ADDRESSES OF THE AUTHORS: Niklas Klinga
(niklas.klinga@holmenpaper.com.) and Hans Höglund
(hans.hoglund@miun.se): Mid Sweden University, Department
of Natural Sciences, Fibre Science and Communication
Network, FSCN, SE-851 70 Sundsvall, Sweden.
Christer Sandberg (christer.sandberg@holmenpaper.com):
Holmen Paper Development Centre, Braviken Paper mill,
SE-601 88 Norrköping, Sweden.
Corresponding author: Niklas Klinga

Consolidation and strength evolution during drying of paper sheets occur due to the development of inter fibre bonds. The creation of inter fibre bonds is however hindered by the presence of water in an early stage of pressing and drying, i.e. at low solids contents. The main mechanisms responsible for strength development in the sheet are then surface tension and adhesive forces (Lyne and Gallay Oct 1954, Lyne and Gallay Dec 1954, Schwarz and Bechtel 2003).

At low solid contents, dewatering is highly restrained by water flow and the press load is thereby taken up as a hydraulic pressure in the sheet. The dewatering changes from being highly flow restricted to more compression restricted when the solids content reaches a range between 35 and $50 \%$. This means that more of the press load is taken up by the fibre network. When pressing at such solids contents, a permanent deformation of the fibre network is achieved even though there is a certain spring back effect once pressure is released (Back 1987a, Back 1987b).

Dewatering can be enhanced by raising the temperature which results in reduced water viscosity and reduced water surface tension which in turn affects both capillary forces and film splitting (Cutshall 1995, Cutshall and Hudspeth 1995, Krook et al. 1996). The increased temperature thus reduces the water flow resistance, leading to an increase in fibre network pressure uptake. An increased temperature also leads to a softening of the fibre network. This is especially seen for pulps with high lignin content, e.g. TMP and CTMP, for which the increased temperature leads to a reduced spring back effect and an increased compressibility of the fibre network (Back 1985, Back 1987a, Back 1987b, Krook et al. 1996, Mendes et al. 2004) due to lignin softening. Hence, increased temperature during pressing leads to improved dewatering which in turn leads to higher outgoing solids content levels from the press section. A combination of raised temperature and pressure leads to increases in sheet density followed by increases in both in-plane and out-of-plane strength (Retulainen et al. 1998, Fellers et al. 2005).

There are commercial techniques for pressing to higher dryness levels available, such as Condebelt drying (Retulainen et al. 1998, Fellers et al. 2005), press drying/impulse drying (Back 1985, Krook et al. 1996, Karlsson 2001, Mendes 2004). These techniques all show promising improvements in paper sheet strength properties, especially for sheets based on pulps with high contents of lignin, but have however only been implemented to a limited extent.

Fibre properties such as fibre length, fibre width, fibre flexibility, content (and quality) of fines etc. have large effects on sheet properties. Earlier studies have shown that, especially for high freeness mechanical pulps, there are often large differences in sheet properties when comparing sheets made according to the conventional ISO method and the Rapid Köthen method (Klinga et al. 2005). The main difference between these methods is that ISO sheets are wet pressed at $400 \mathrm{kPa}$ and then dried at room temperature (ISO 5269-1 1998), whereas Rapid Köthen sheets are pressed and simultaneously dried at 96 $\mathrm{kPa}$ and $93^{\circ} \mathrm{C}$ (ISO 5269-2 1998). The large difference in sheet properties between the methods has been attributed to the softening of lignin, which makes the fibres more flexible and give a higher density and strength for Rapid Köthen sheets (Nygren et al. 2003, Klinga et al. 2005). There is however another, probably very important, difference between the methods, namely what solids contents the sheets have at finished pressing. ISO sheets 
are wet pressed to approximately $50 \%$ dryness before being dried in a conditioning room. The Rapid Köthen sheets are on the other hand pressed and dried until the sheets are dry. This fact has raised questions regarding in what solids content interval most of the consolidation and strength development occurs during pressing of mechanical and chemithermomechanical pulp fibres with a relatively high inherent stiffness.

\section{Experiment}

For the purpose of this paper, sheets from two different mechanical pulps and one chemithermomechanical pulp and their respective long fibre fractions were pressed at high temperature to different dryness levels, from some $30 \%$ solids content to fully dry. The sheets were then dried and conditioned without pressing to final dryness in a conditioning room prior to testing of physical properties. This was performed with the objective of evaluating the consolidation and evolution of strength properties with respect to dryness after a press section.

The pulps used were spruce (Picea abies) pulps with different freeness levels. HTCTMP is a fluff pulp intended for the use as absorbing material in hygiene products. TMP 3 is used as middle layer in paperboard and TMP1 is used for directory paper. Pulp properties are shown in Table 1 .

Table 1. pulp properties

\begin{tabular}{lccc}
\hline Pulp & HTCTMP & TMP3 & TMP1 \\
\hline SEC (kWh/admt) & $\sim 600$ & $\sim 1200$ & $\sim 2400$ \\
CSF (ml) & 699 & 250 & 44 \\
Fibre length (length & & & \\
weighted, mm), Fiberlab & & & \\
BMcNett $>30(\%)$ & 3.07 & 2.15 & 2.41 \\
BMcNett 30-50 (\%) & 64.8 & 34.2 & 33.5 \\
BMcNett 50-100 (\%) & 15.2 & 23.3 & 17.3 \\
BMcNett 100-200 (\%) & 7.5 & 13.5 & 9.1 \\
BMcNett <200 (\%) & 1.0 & 1.9 & 2.5 \\
& 11.6 & 27.0 & 37.6 \\
\hline
\end{tabular}

The pulps were fractionated on a 50 mesh wire in a fractionation device similar to, but larger than, a Britt Dynamic Drainage Jar. The long fibre fractions are distinguished from the whole pulps by the addendum R50 in figure legends etc.

Sheets with a grammage of $65 \mathrm{~g} / \mathrm{m}^{2}$ were formed in a conventional ISO sheet former, without recirculation of fines. The sheets were then adhered to metal couch plates and, one at a time, pressed and dried in a modified Rapid Köthen dryer, Fig 1.

The drying principle for this unit is similar to a standard Rapid Köthen dryer, i.e. hot water is transferred through the lid and the heat is transferred to the sheet via a silicon rubber membrane. The modified Rapid Köthen dryer is equipped with a high pressure pump. This allows pressing of the sheets at higher pressure compared to conventional Rapid Köthen sheets, which according to standard are pressed and dried at $96 \mathrm{kPa}$ and $93^{\circ} \mathrm{C}$ (ISO 5269-2 1998). The pressure was set by means of the adjustable valve shown in Fig 1 .

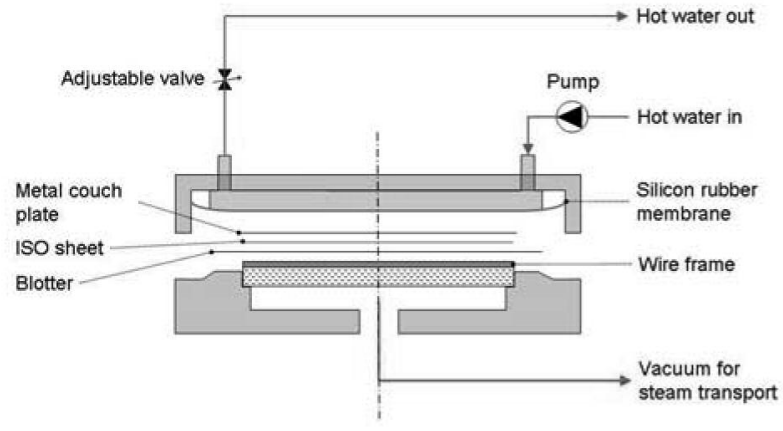

Fig 1. Schematic sketch of the modified Rapid Köthen dryer.

For the purpose of this trial, the sheets were pressed at $400 \mathrm{kPa}$ and $93^{\circ} \mathrm{C}$ to different dryness levels, simply by varying the time for pressing. The sheets were instantly weighed once pressing was finished. All sheets were then conditioned in accordance with ISO 187 , i.e. $23^{\circ} \mathrm{C}$ and $50 \%$ R.H. (ISO 187 1990). Once dried and conditioned the sheets were tested for density, tensile strength and Zstrength. The dryness was calculated from $E q 1$.

$$
\text { dryness }(\%)=100 \cdot \frac{0.9 \cdot \text { conditioned weight }}{\text { weight after pressing }}
$$

\section{Results and Discussion}

Sheets were formed from both the whole pulps and their respective long fibre fraction, defined as the pulp retained on a 50 mesh wire in a fractionation device similar to, but larger than, a Britt Dynamic Drainage Jar. Approximately $85 \%, 70 \%$ and $60 \%$ of the pulps were retained on the 50 mesh wire during fractionation from HTCTMP, TMP3 and TMP1 respectively.

All sheets were dried to the final dryness in a conditioning room before the physical properties were tested. The dryness values reported in the following figures were obtained immediately after pressing at $400 \mathrm{kPa}$ and $93^{\circ} \mathrm{C}$. Figures 2 to 4 show density as a function of dryness after pressing for both whole pulps and long fibre fractions of the HTCTMP, TMP3 and TMP1 respectively. Properties of ISO sheets are added to the figures for comparison and are shown as larger points.

All pulps experienced an increase in density when the sheets were pressed to higher dryness levels. The fibres obviously sprung back when pressing was terminated after short times, i.e. at low dryness levels. The fibres were however locked in their positions when the sheets were pressed and dried for longer times and to higher dryness levels, resulting in higher density due to a higher degree of bonding between the fibres. The dryness level to which the sheets are pressed is however not the only driver for the degree of densification. Density levels for ISO sheets, which were also pressed at $400 \mathrm{kPa}$ but at room temperature, are lower than for sheets pressed at $93^{\circ} \mathrm{C}$, when compared at the same dryness levels, Figs 2 to 4 . The high temperature softens lignin which makes fibres flexible and more compressible, hence higher densification at higher temperatures.

The difference in density between the long fibre fractions and the whole pulps illustrates that the 


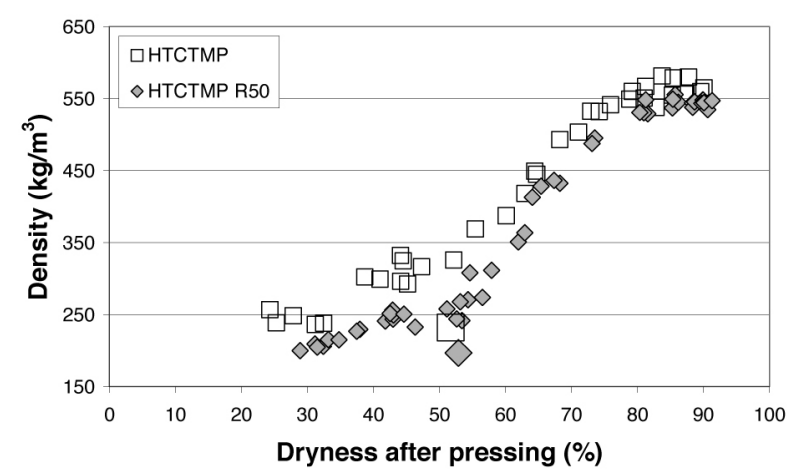

Fig 2. Density (measured on dry sheets) as a function of dryness (measured immediately after pressing at $400 \mathrm{kPa}$ and $93^{\circ} \mathrm{C}$ ) for HTCTMP and HTCTMP R50. ISO sheets are represented by large points.

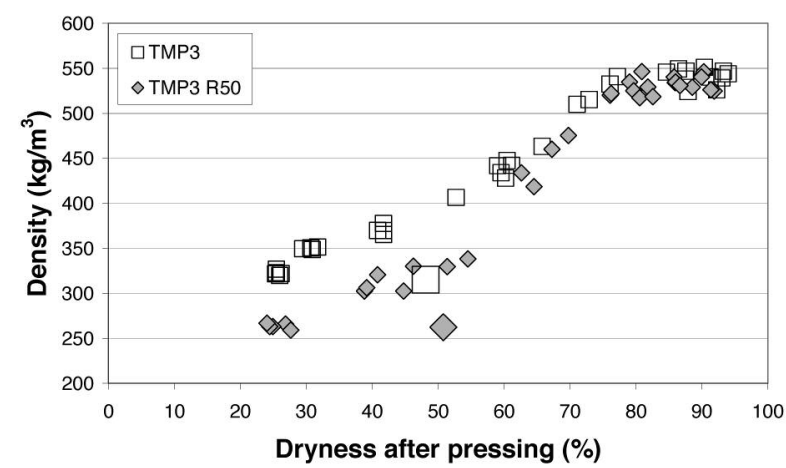

Fig 3. Density (measured on dry sheets) as a function of dryness (measured immediately after pressing at $400 \mathrm{kPa}$ and $93^{\circ} \mathrm{C}$ ) for TMP3 and TMP3 R50. ISO sheets are represented by large points.

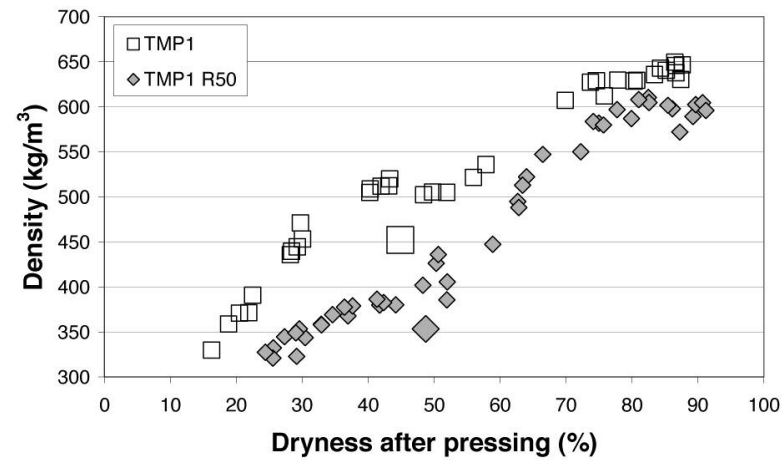

Fig 4. Density (measured on dry sheets) as a function of dryness (measured immediately after pressing at $400 \mathrm{kPa}$ and $93^{\circ} \mathrm{C}$ ) for TMP1 and TMP1 R50. ISO sheets are represented by large points.

importance of fines decreased with increased dryness after pressing. This may be explained by the fact that fines contribute to inter fibre bonding and this effect could be seen as a higher density for the whole pulps at low dryness levels. When the fibres were forced together at higher dryness levels during pressing, it was possible to achieve good bonding between the fibres even when there was a reduced amount of fines. Fig 5 shows density as a function of the dryness level for all long fibre fractions.

The stiff long fibres from the HTCTMP gave sheets with the lowest density at low dryness levels, followed by TMP3 and then TMP1. Fig 5 clearly illustrates the difference in fibre flexibility between the pulps. This difference however diminishes when the sheets are pressed to

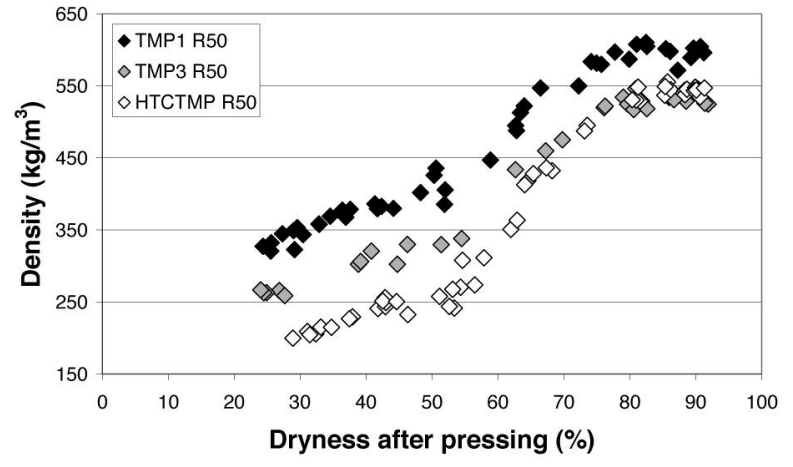

Fig 5. Density (measured on dry sheets) as a function of dryness (measured immediately after pressing at $400 \mathrm{kPa}$ and $93^{\circ} \mathrm{C}$ ) for all long fibre fractions.
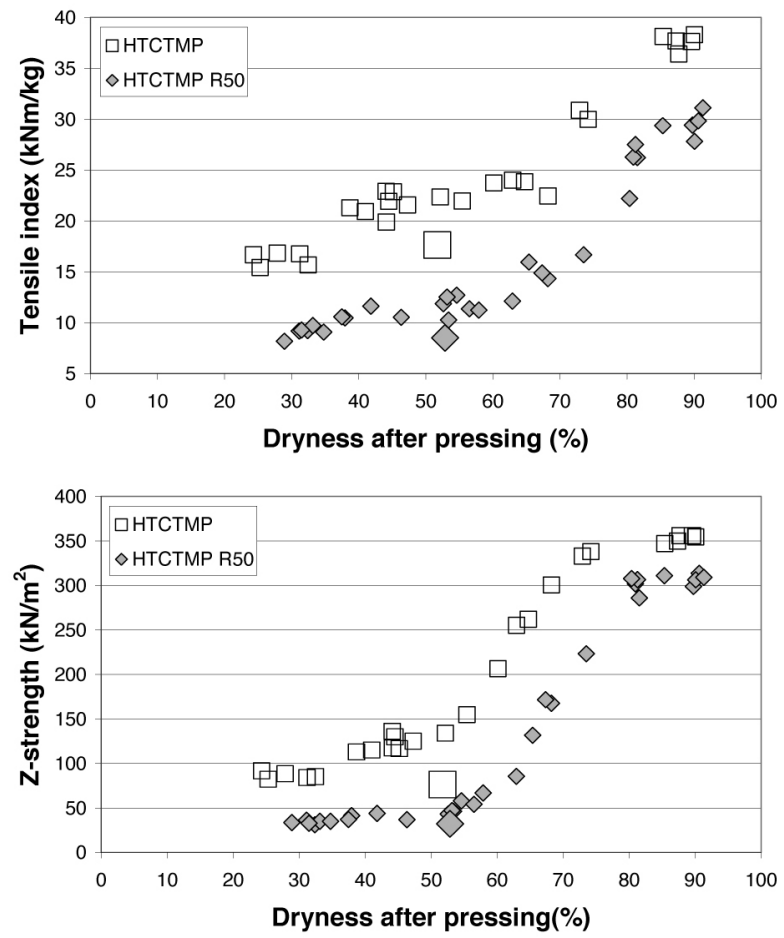

Fig 6. Tensile index (top, measured on dry sheets) and Z-strength (bottom, measured on dry sheets) as functions of dryness (measured immediately after pressing at $400 \mathrm{kPa}$ and $93^{\circ} \mathrm{C}$ ) for HTCTMP and HTCTMP R50. ISO sheets are represented by large points.

higher dryness levels, i.e. when the fibres are forced together and locked in their bonding positions.

The tensile strength and the internal bond strength, measured as Z-strength, are shown in Figs 6, 7 and 8 for the HTCTMP, TMP3 and TMP1 respectively. Properties of ISO sheets are added to the figures for comparison and are shown as larger points.

Pressing the sheets to high solid content levels by high pressure and temperature raised both tensile index and Zstrength for all whole pulps and long fibre fractions. This was expected and in line with earlier experiences (Klinga et al. 2005). The most interesting finding from these trials was however that the increase in strength was not proportional with increased solids content, especially for the long fibre fractions when looking at the Z-strength development. For all long fibre fractions and the HTCTMP whole pulp, there was a distinct inflection of the curve at a dryness level of some $50 \%$. This means that the paper 

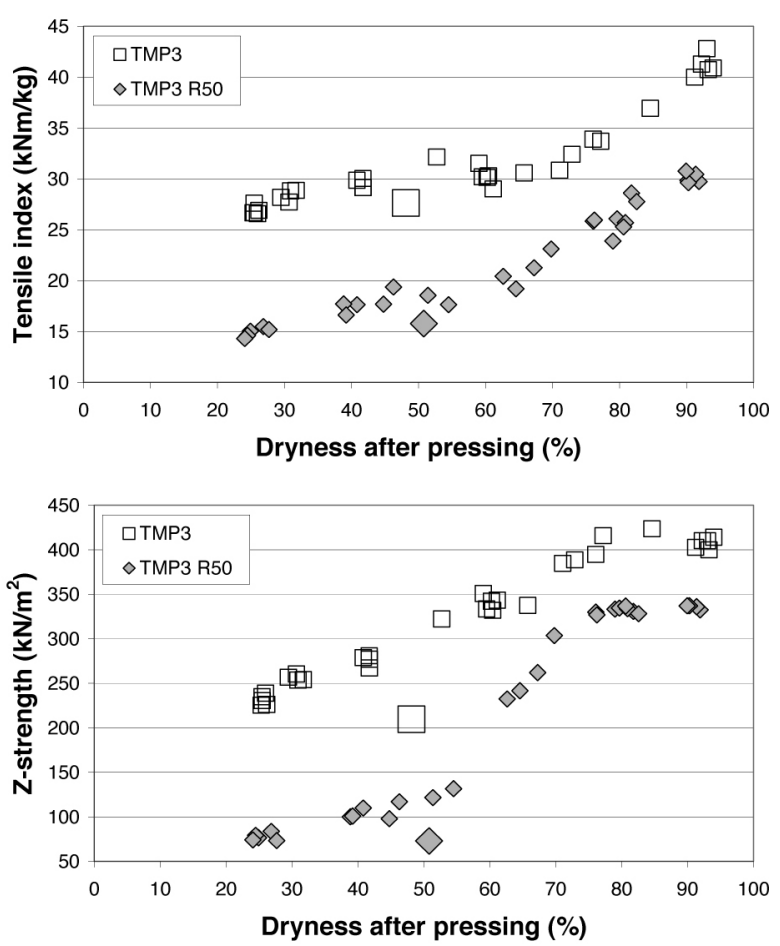

Fig 7. Tensile index (top, measured on dry sheets) and Z-strength (bottom, measured on dry sheets) as functions of dryness (measured immediately after pressing at $400 \mathrm{kPa}$ and $93^{\circ} \mathrm{C}$ ) for TMP3 and TMP3 R50. ISO sheets are represented by large points.

sheets were most influenced by pressing and drying at dryness levels above some $50 \%$, i.e. above the solids content level where dewatering proceeds from being flow restricted to more compression restricted (Back 1987a, Back 1987b). This is also in analogy with earlier studies on changes of mechanical properties during drying of laboratory sheets (Htun 1984, Htun et al. 1985).

The most important dryness content interval for internal strength development was found to be between 50 and $80 \%$. This trend could also be seen for the density and the tensile index for HTCTMP, Fig 2 and 6, and TMP3, Fig 3 and 7. For the whole pulps, except for HTCTMP which contained a very small amount of fines, the inflection was not as abrupt as for the long fibre fractions. This can be explained by the fact that fines contribute to inter fibre bonding even at low dryness levels.

Strength levels for the ISO sheets, which were also pressed at $400 \mathrm{kPa}$ but at room temperature, were lower when compared at the same dryness levels than for sheets pressed at $93^{\circ} \mathrm{C}$. The high temperature softens lignin which makes fibres flexible and more compressible, hence the higher strength levels at higher temperatures. The difference between ISO sheets and sheets pressed at high temperature was however smaller for TMP1 than for HTCTMP and TMP3, Figs 6 to 8 . This illustrates that the influence of temperature on fibre softening is more pronounced for high freeness pulps with mostly stiff fibres than for low freeness pulps with higher contents of flexible fibres.

In the dryness interval between approximately 25 and $50 \%$, some inter fibre bonds are created, of which many are probably broken once pressure is released since a lot of water is still present in the sheet and combined with a spring back effect of the fibres. This spring back effect is
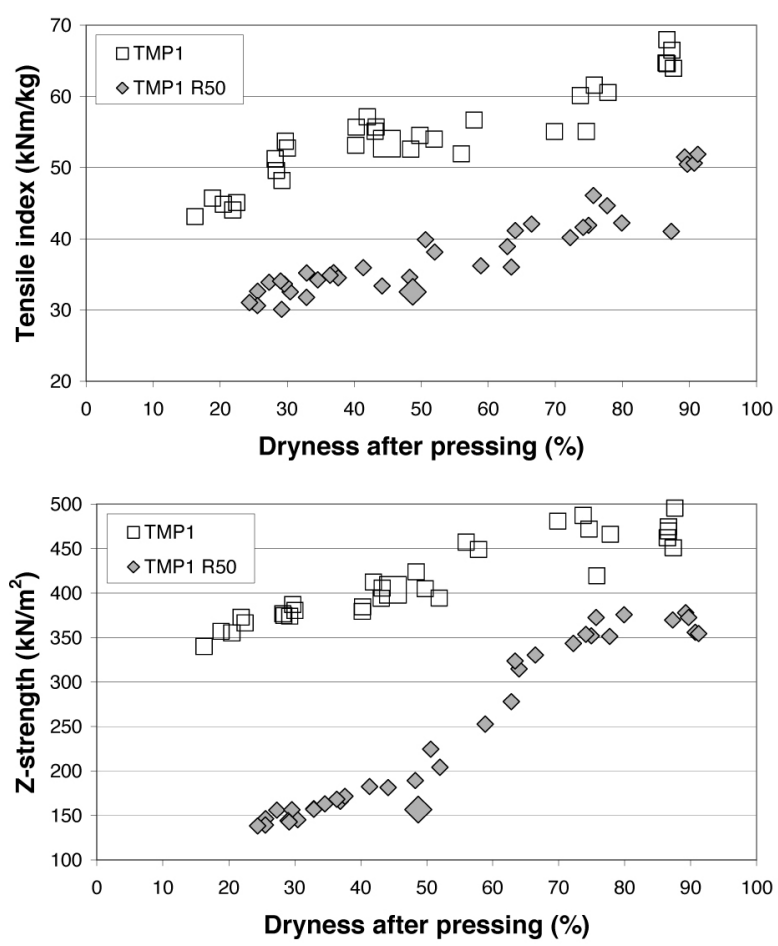

Fig 8. Tensile index (top, measured on dry sheets) and Z-strength (bottom, measured on dry sheets) as functions of dryness (measured immediately after pressing at $400 \mathrm{kPa}$ and $93^{\circ} \mathrm{C}$ ) for TMP1 and TMP1 R50. ISO sheets are represented by large points.

more pronounced for the stiff HTCTMP fibres compared to the more flexible and compressible TMP1 fibres, hence the lower density for HTCTMP. When reaching some $50 \%$ dryness, a sufficient amount of water has been removed and the temperature in the sheet has approached the softening temperature of lignin. This is the phase where probably most inter fibre bonding occurs. The absence of water film allows the fibres to get into contact and, due to lignin softening which enhances a better adhesion between fibre surfaces, these do not spring back as much. As dryness increases, the fibres are locked in their positions and more inter fibre bonds are created. When reaching the fibre saturation point, which for softwoods is found in the solids content range between 70 and 75\% (Rydholm 1965, Parham 1983), the remaining water is bound to the fibre wall and the strength increase is after this point very small, especially when looking at Z-strength.

Pulps from high temperature processes (e.g. HTMP and HTCTMP) are, due to their high content of long and stiff fibres with highly lignified surfaces, considered to have poor bonding ability (Atack 1972). Earlier studies (Pynnönen et al. 2002, Pynnönen et al. 2004, Klinga et al. 2005) however indicate that highly lignified fibre surfaces have a high bonding potential in a sheet structure when the effect of fibre stiffness is reduced. To shed some light upon how long fibres from different pulp types perform, Fig 9 shows tensile strength (top) and Zstrength (bottom) for the long fibre fractions included in this trial.

The long fibres from TMP1, which were highly flexible and highly fibrillated, gave sheets with the highest strengths, especially tensile strength. When looking at the Z-strength, however, TMP1 long fibres still 

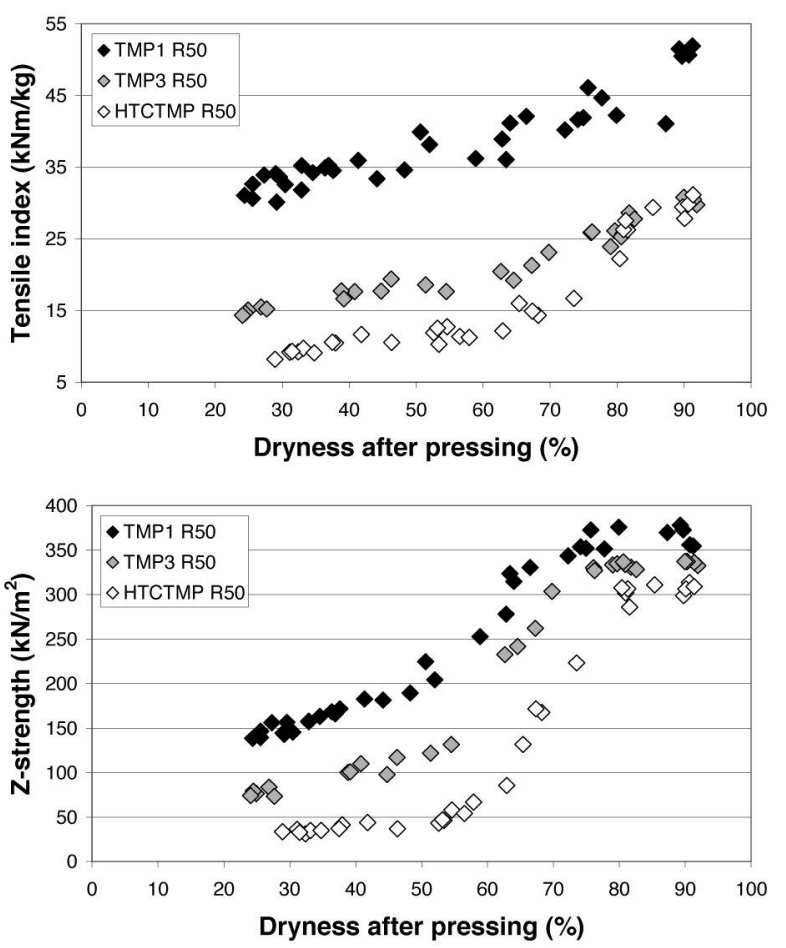

Fig 9. Tensile index (top, measured on dry sheets) and Z-strength (bottom, measured on dry sheets) as a function of dryness (measured immediately after pressing at $400 \mathrm{kPa}$ and $93^{\circ} \mathrm{C}$ ) for all long fibre fractions

delivered the highest strength although the difference compared to the HTCTMP was surprisingly small when pressing the sheets to high dryness levels. This indicates that pulps from high temperature processes do have a high out-of-plane strength potential, as long as the softened surfaces are allowed to come closer.

The measurements on the elongation at rupture showed a quite large experimental variation compared to the real variation. The general trend was however that the elongation at rupture was preserved for the low freeness pulps (i.e. TMP3 and TMP1) and increased for the high freeness pulp (i.e. HTCTMP) when pressing the sheets to higher solids contents.

Optical properties were not measured on the sheets due to the fact that this experiment was part of a project focusing more on mechanical pulps for the use as middle layer in board products than pulps for the use in printing paper. Hence optical properties were not of primary interest. Earlier studies found in literature do however often report that pressing and drying at raised temperature and pressure does lead to a certain loss in light scattering coefficient, which in turn affects brightness and opacity negatively (Back 1987a, Back 1987b).

This trial has shown that most of the development of strength properties occurs in the dryness interval between 50 and $80 \%$. The fact that most paper and board machines only press the sheet to some $50 \%$ dryness, before feeding the sheet into the drying section, implies that much of the inherent strength potential of mechanical pulps is unexploited. There are commercial techniques for pressing to higher dryness levels available, such as Condebelt drying (Retulainen et al. 1998, Fellers et al. 2005), press drying/impulse drying (Back 1985, Krook et al. 1996, Karlsson 2001, Mendes 2004). These techniques have however only been implemented to a limited extent. Further research on pressing to higher dryness levels will in the future be continued at FSCN at Mid Sweden University.

\section{Conclusions}

For the purpose of this paper, sheets from two different mechanical pulps and one chemithermomechanical pulp and their respective long fibre fractions were pressed and dried systematically to different dryness levels, from some $30 \%$ solids to fully dry. The sheets were then dried and kept in a conditioning room prior to testing of physical properties. This was performed with the aim of evaluating the consolidation and development of final strength properties as a function of dryness levels after a press section in a paper machine. The essence of the results is presented below.

- All pulps experienced an increase in density and strength properties when the sheets were pressed to higher dryness levels.

- The fibres obviously sprung back when pressing was terminated after short times, i.e. at low dryness levels. However, the fibres were locked in their positions when the sheets were pressed and dried for longer times and to higher dryness levels, resulting in higher density and strength values due to a higher degree of bonding between the fibres.

- When the fibres were forced together during pressing to higher dryness levels, it was possible for all pulps to achieve high out-of-plane strength even when there was an absence of fines.

- The increase in strength was not linear with increasing dryness after pressing, especially for the long fibre fractions when looking at the Z-strength development. For all long fibre fractions and the HTCTMP whole pulp, there was a distinct inflection of the curve when the solids content reached a level of some $50 \%$. The most important dryness interval for internal strength development was found between 50 and $80 \%$. This trend could also be seen in the density and the tensile index for HTCTMP and TMP3. For whole pulps, except for HTCTMP which contained a very small amount of fines, the inflection was not as abrupt as for the long fibre fractions, this can be explained by the fact that fines contributed to inter fibre bonding even at low dryness levels.

- The long fibres from TMP1, which were highly flexible and highly fibrillated, gave sheets with the highest strengths, especially tensile strength. When looking at Z-strength, however, TMP1 long fibres still delivered the highest strength although the difference compared to HTCTMP was surprisingly small when pressing the sheets to high dryness levels. This indicates that pulps from the high temperature processes do have a 
high out-of-plane strength potential, as long as the effect of fibre stiffness is reduced.

- Most paper and board machines only press the sheet to some $50 \%$ dryness, before the sheet is fed into the drying section. The results from this trial imply that much of the inherent strength potential of mechanical pulps appears to be unexploited. Further research on pressing to higher dryness levels will in the future be continued at FSCN at Mid Sweden University.

\section{Acknowledgements}

The authors would like to thank the staff at SCA Graphic Research for their skilful assistance in pulp and paper testing. Lorna Casson at Iggesund Paperboard Workington, Holmen $A B$, is acknowledged for linguistic revision. Holmen $A B$ and the Swedish Knowledge Foundation are acknowledged for financial support through the FSCN Industrial Mechanical Pulp Research College at Mid Sweden University.

\section{Literature}

Atack, D. (1972): On the characterization of pressurized refiner mechanical pulps, Svensk Papperstidning, 3, 89-94.

Back, E.L. (1985): Press drying compared to other means of densifying paper, Tappi J. 68(3), 92-96.

Back, E.L. (1987a): Higher press dry content with or without increased density in the paper, Svensk Papperstidning, 6(26), 116-125.

Back, E.L. (1987b): Using the wet press to optimise paper properties, Paper Technol. Ind. 28(3), 454-459.

Cutshall, K. (1995): Sheet consolidation \& hot pressing, Practical Aspects of Pressing \& Drying Short Course, 229-237.

Cutshall, K. and Hudspeth, D. (1995): Hot pressing (TAPPI seminar discussion 1988), Practical Aspects of Pressing \& Drying Short Course, 239-250.

Fellers, C., Panek, J., Retulainen, E. and Haraldsson, T. (2005): Condebelt drying and linerboard performance, Nord. Pulp Paper Res. J. 20(1), 87-92.

Htun, M. (1984): Changes in in-plane mechanical properties during drying of handsheets, Tappi J. 67(9), 124-127.

Htun, M., de Ruvo, A. and Fellers, C. (1985): The Dynamic Mechanical Behavior of Paper during Drying, J. Appl. Polym. Sci. 30, 1597-1604.
Karlsson, M. (2001): Drying of paper - an overview, the state of paper drying knowledge, 12th Fundamental Research Symposium, Oxford, Session 4: Pressing and Drying, 709-736.

Klinga, N., Sandberg, C. and Höglund, H. (2005): Sheet properties of high yield pulps related to different pressing and drying conditions, International Mechanical Pulping Conference, Oslo, Norway, June 7-9, 344-348.

Krook, R., Stenström, S. and Hollmark, H. (1996): Some effects of press drying on paper properties, Nord. Pulp Paper Res. J. 3, 141-151.

Lyne, L.M. and Gallay, W. (Oct. 1954): Studies in the Fundamentals of Wet-Web Strength, Pulp Paper Mag. Can., 128-134.

Lyne, L.M. and Gallay, W. (Dec. 1954): Fibre Properties and Fibre-Water Relationships in Relation to the Strength and Rheology of Wet Webs, Pulp Paper Mag. Can., 158-171.

Mendes, P., Belgacem, N. and Bloch, J.-F. (2004): Impulse Drying Technology: the state of the art and the recent advances, ATIP 58(1), 25-34.

Nygren, 0., Bäck, R. and Höglund, H. (2003): On characterization of mechanical and chemimechanical pulps, International Mechanical Pulping Conference, Quebec City, Canada, June 2-5, 97-103.

Parham, R.A. (1983): Wood physical properties, Pulp and Paper Manufacture, Third Edition, Vol 1; Properties of Fibrous Raw Materials and their Preparation for Pulping, Tappi CPPA, 47.

Pynnönen, T., Paltakari, J., Hiltunen, E., Laine, J.E. and Paulapuro, H. (2002): Effect of press drying on sheet properties of high-temperature thermomechanical pulp (HTMP), Appita J. 55(3), 220-223.

Pynnönen, T., Hiltunen, E., Paltakari, J., Laine, J.E. and Paulapuro, H. (2004): Good bonding for low-energy HT-CTMP by press drying, Pulp Paper Can. 105(3), T57-T61.

Retulainen, E., Merisalo, N., Lehtinen, J. and Paulapuro, H. (1998): Effect of Condebelt press drying on sheet structure and properties, Pulp Paper Can. 99(1), T20-T24.

Rydholm, S.A. (1965): Pulping Processes, Interscience publishers, 65.

Schwarz, M. and Bechtel, K. (2003): Initial structural strength in sheet formation, Wochenblatt für Papierfabrikation, 131(16), 950-957.

SS-EN ISO 5269-1 (1998): Pulps - Preparation of laboratory sheets for physical testing - Part 1: Conventional sheet-former method.

SS-EN ISO 5269-2 (1998): Pulps - Preparation of laboratory sheets for physical testing - Part 2: Rapid-Köthen method.

SS-EN ISO 187 (1990): Paper, board and pulps - Standard atmosphere for conditioning and testing and procedure for monitoring the atmosphere and conditioning of samples.

Manuscript received May 28, 2007 Accepted October 1, 2007 